\section{MARÍA MARTINS, LA ÚNICA SURREALISTA DE BRASIL}

MARÍA MARTINS, THE ONLY SURREALIST WOMAN IN BRAZIL

Lilian Ribeiro

Universidad de Sevill

\section{Resumen:}

Este artículo pretende mostrar la creación This article aims to show the creation of surrealista de la escultora brasileña María surreal Brazilian sculptor Maria Martins, to Martins, revelar el predominio del cuerpo y la reveal the predominance of the female body sexualidad femenina en su producción. Antes and female sexuality in her production but de adentrarnos en el análisis de sus obras, before we get into the analysis of her artworks, de adentras es necesario hace un resum de y situarla al contexto de las artes plásticas, como hemos realizado en esta investigación.

Palabras claves: Surrealista, escultora, femenino, brasileña, sexuality.

cuerpo, sexualidad.
En Brasil, el movimiento surrealista llegó de una forma tenue, fue una tendencia que casi no existió, debido a que cuando nació en Europa, de la mano de André Breton, este país lo rechazó, lo tomó como una blasfemia. Pero también porque el país sudamericano vivía un período de un alto nacionalismo, una época en la que estaba de moda exaltar el sentimiento patriótico, un tiempo para buscar las "raíces primitivas". A pesar de todo, este período quedó enmarcado como la época del Modernismo Brasileño y del Movimiento Antropofágico 1 .

En las artes, predominaba la antropofagia de Mario y Oswald de Andrade², además de Tarsila do Amaral ${ }^{3}$, entre otros. Todos estaban cansados de beber de las fuentes francesas y de las inglesas. Querían un arte brasileño. Sin embargo, es evidente que la influencia surrealista, a pesar de los obstáculos históricos y políticos, había llegado también a Brasil y había conseguido inspirar a algunos artistas, mostrando el imaginario popular brasileño. Los participantes de la primera fase del Movimiento Modernista Brasileño las empiezan a absorber y a desarrollar las ideas de la corriente entre 1920 y 1930

Antropofagicamente", devorado y esculpido en obras como el cuadro titulado "Cuca" obra de Tarsila do Amaral. Su cuadro "Abaporu”, de 1928, inaugura el "Movimiento Antropofágico" en los artistas plásticos del país. El surrealismo brasileño destacó

1 El Movimiento Antropofágico consistió en devorar, tragar el modelo modernista europeo, absorber las calidades europeas y a partir de ahí crear un arte nacional, valorando la cultura brasileña.

2 Los hermanos Andrade: Mário Raul de Morais Andrade (São Paulo, 9 de octubre de 1893 - íbid., 25 de febrero de 1945) fue un poeta, novelista, ensayista y musicólogo brasileño. Fue uno de los miembros fundadores del Modernismo Brasileño. En 1922 participó activamente en la Semana de Arte Moderno de São Paulo, que tuvo una gran influencia en la renovación de la literatura y de las artes en Brasil. Su segundo libro de poeśa, Paulicéia desvairada, publicado ese mismo año, marca para muchos el inicio de la poeśa modernista brasileñ.

José Oswald de Sousa Andrade, conocido como Oswald de Andrade (São Paulo, 11 de enero de 1890 - íbid., 22 de octubre de 1954), fue un poeta, ensayista y dramaturgo brasileño. Fue uno de os promotores de la Semana de Arte Moderno de São Paulo, en 1922 y es uno de los nombres más destacados del Modernismo Brasileño en la literatura. Estuvo casado con Tarsila do Amaral.

3 La artista plástica paulista (nace en São Paulo) es la pintora más representativa de la primera fase del Movimiento Modernista Brasileño.

4 El razonamiento caníbal, retomado y metaforizado por un grupo de artistas brasileños, tuvo como objetivo devorar lo mejor de su cultura y de la modernidad europea, en un intento por separarse de la costumbre decimonónica de imitar las tendencias occidentales. Muchos de los artistas y escritore pertenecientes a este grupo se formaron en escuelas europeas y allí aprendieron las corrientes artísticas más novedosas; sin embargo, al volver a su país las asimilaron desde la identidad local. Tal fue el caso de Tarsila do Amaral. Véase: http://www.operamundi-magazine.com/2012/01/ movimiento-antropofagico-devorar-y-devorarse.html. Acceso el 02/02/2014.

5 Cuadro pintado en 1924. En el lienzo se describe la tierra brasileña llena de tradición, despierta el sentimiento de "brasileñidad" y se encuadra en el movimiento Pau-Brasil creado por Oswald de Andrade. Vid. http://www.tarsiladoamaral.com.br/versao_antiga/historia.htm. Acceso el 02/02/2014. 
fundamentalmente de la mano de María Martins, considerada una de las principales escultoras surrealistas, quizás la única realmente surrealista.

\section{María Martins, la única artista plenamente surrealista de Brasil}

El papel de la mujer en el arte sigue siendo reivindicado y continúan escribiéndose artículos sobre la falta de reconocimiento de las obras de las artistas contemporáneas en comparación con el de sus colegas hombres. Por este motivo destacó la obra de la brasileña María Martins, que ni siquiera fue reconocida a título póstumo, a pesar de la cantidad y de la inmensa calidad de sus esculturas.

Antes de adentrarnos en el análisis de sus obras, se hace necesario empezar con un resumen biográfico para situar todos estos datos en el contexto de las artes plásticas.

María de Lourdes Alves Perreira Barbosa fue una brasileña cosmopolita que llevó al arte la cultura popular, la cultura híbrida y la cultura marginada que se dio en Brasil en los años cuarenta. Enfocó también su arte hacia un escenario internacional conflictivo, un escenario marcado por la Segunda Guerra Mundial.

Nació el 7 de noviembre de 1894 en la ciudad de Campanha- Minas Gerais-Brasil. Fue escultora, dibujante, pintora, escritora, periodista y se dedicó a la música. Está considerada como la única artista brasileña plenamente surrealista. Tuvo una vida acomodada, como toda chica burguesa de su tiempo, y estudió en un colegio de monjas, en el colegio Sion en Petrópolis. Allí recibió una educación basada en el prototipo de mujer hogareña: una buena ama de casa, que viviese como una madre acorde y una esposa ejemplar. También estudió piano y uno de sus primeros sueños fue el de ser concertista. Su padre le enseñó a amar los versos de Goethe y de Dante, antes incluso de aprender a leer. Fue educada para el matrimonio, pero ella fue una excepción de la realidad colectiva, fue una mujer muy avanzada que rompió con los moldes patriarcales de la época.

María Martins se casó por primera vez en 1915 con el jurista e historiador Otávio Tarquínio de Sousa ${ }^{6}$, un marido conservador del que se separó en 1924 por tener una relación conflictiva. Ella era activa e independiente. Con su primer marido tuvo una hija, Lúcia. Tras el matrimonio fracasado viajó a París para acompañar a su padre, que iba a recibir un tratamiento médico. En ese momento, empieza a frecuentar los círculos intelectuales parisinos y comienza a mantener sólidas amistades con pintores, artistas e intelectuales.

En 1926, contrajo segundas nupcias con el diplomático Carlos Martins Pereira e Sousa, embajador de Brasil antes y después de la Segunda Guerra Mundial, primero

6 Véase:http://pt.wikipedia.org/wiki/Ot\%C3\%A1vio_Tarqu\%C3\%ADnio_de_Sousa, Y http://www. dec.ufcg.edu.br/biografias/OtavTaSo.html. Acceso el 02/02/2014. en \apón y posteriormente en diferentes países de Europa. Según algunos biógrafos de la escultora, ésta mantuvo un matrimonio abierto con su segundo marido, lo que le permitió tener algunos amantes, ya que gozaba de mucha libertad. Algo impensable en este período, tiempo en el que la mujer tenía la obligación de conservar y mantener el matrimonio de un modo feliz, aunque tuviese que anularse civilmente.

En cuanto a su carrera profesional, los comienzos de la artista, de 1930 hasta 1939 fueron muy lentos. Eso sí, tuvo la suerte de hacerlo en diferentes capitales: Quito, Copenhague, Tokio y Bruselas, donde vivió con Carlos Martin y donde ejerció de embajadora consorte. También tuvo dos hijas con él: Nora y Ana María. El hecho de ser mujer le dificultó el ingreso inmediato en el mundo "masculino" del arte, a pesar de sus buenos contactos -estaba casada con un hombre muy influyente- y a pesar de que provenía de una familia acomodada. Tenía los mismos problemas con los que se encontraban todas las mujeres que habían tenido una educación represora y conservadora en la sociedad patriarcal de ese período. Además, tuvo que compaginar las funciones de madre y artista: se enfrentó, así, a la doble jornada laboral.

Como una forma de romper con lo establecido, tuvo un romance muy intenso y conocido con Marcel Duchamp. Él le dedicó los trabajos, "Le paysage fautif" $y$ "Etant donnés"‥ La relación se puede comprobar por las cartas que éste le dirigió요. Conoció a Picasso y Mondrian, que también fue su amante; entrevistó a Mao-Tse Tung. Además de ser la representante de Brasil en la Conferencia de la UNESCO en Nueva Delhi. En este período estaba divorciada, tenía otro marido y un amante, además participaba en encuentros intelectuales. Ya se la conocía por sus esculturas a principios del $\underline{\text { siglo }}$ $\underline{X X}$, un hecho impensable para una mujer². Martins se aleja del discurso dominante, el del hogar feliz, de los roles femeninos más convencionales, el de esposa sumisa y el de madre entregada. Rompe con lo doméstico de lo femenino, un eterno femenino construido sobre la base de intereses patriarcales ${ }^{10}$.

La escultora al principio se interesó por la música; posteriormente estudió pintura en París. A los treinta años se interesó por la escultura. María Martins, en Francia comenzó a trabajar la madera y en Japón con el arte de la cerámica. Perfeccionó su

7 Antelo, Raúl (2006), Maria con Marcel: Duchamp en los trópicos, Siglo XXI Editores, pp.326., y Parcerisas, Pilar (2009), Duchamp en España: Las claves ocultas de sus estancias en Cadaqués, Siruela, pp.136.

8 Los originales pertenecen a Nora Martins Lobo, hija mayor de la artista que vive en São Paulo, a la que estoy agradecida. Asimismo, el Museo de Arte de Filadelfia cuenta con algunas copias, cuyo acceso está restringido. La correspondencia no está datada, pero fueron escritas entre 1948 y 1951.

9 Arruda Callado, Ana (2004), Maria Martins: uma biografia, Gryphus, p.189.

10 Amorós, C., y Miguel, A (2007), Teoría feminista: de la Ilustración a la globalización. De la Ilustración al segundo sexo, 2a․ ed, Madrid, Minerva, pp. 250 y 265. y Arriaga, M (org.) (2004), "Feminismos e Interculturalidad", en Fernández Carro, S. "La política de lo cotidiano (arte femenino contra la ideología de esferas separadas", en V Congreso Internacional de la Asociación Universitaria de Estudios de las Mujeres, Sevilla, Arcibel Editores, pp. 33-39. 
técnica en Bélgica con el escultor Oscar Jespers (1887 - 1970). En 1936 aprendió a modelar la terracota.

En 1939 se traslada, con Carlos Martins, a Washington D.C. Posteriormente, a Nueva York, donde estudia escultura con Jacques Lipchitz (1891 - 1973), época en la que comenzó a utilizar el bronce. Este material se convirtió a partir de entonces en el principal soporte de su obra ${ }^{11}$

En 1941, participa en el Philadelfia Museum of Art y en ese mismo año expone algunas obras en la Latin American Exhibition of Fine Art, en el Riverside Museum of Art "Samba"12, “São Francisco"13 y “À procura da luz"14.

En 1942 hace su primera exposición individual en la Corcoran Art Gallery, en Washington, donde presentó 18 esculturas figurativas realistas con temas de la cultura brasileña y de la religión, en materiales diversos (yeso, madera, terracota y bronce). Entre ellas, expone obras como "Salomé" 15 y el "Christo" $\underline{16}$. Además, estableció su estudio en Nueva York, donde dio clases con Jacques Lipchitz (1891 - 1973) y Stanley William Hayter $(1901-1988)^{17}$. En ese momento, la ciudad vive un clima de efervescencia artística, debido a la emigración de varios artistas europeos, que allí se establecen para escapar de la II Guerra Mundial. Tal vivencia lleva a la artista a absorber nuevos contenidos, incorporando elementos surrealistas. Hasta entonces, su obra no tenía un estilo definido; el erotismo estaba presente en las piezas, pero no de manera explícita. Algunas obras se centraban en personajes extraídos de las leyendas brasileñas que relatan historias con contenido erótico, de ahí que su obra se pueda vincular con e erotismo, como sería el caso de "Yara"1ㅗ (1941, bronce). La exploración de la sexualidad

11 Arruda Callado, Ana (2004), op. cit., p.189., y Cancel, Luis R. (1988), El Espíritu latinoamericano: arte y artistas en los Estados Unidos, 1920-1970. El Museo de Artes del Bronx en asociación con H.N Abrams, p.344.

12 Farina, Maria S.E (2008), Identidade e a arte em Maria Martins, (Dissertação de mestrado em Interunida www.dominiopublico gov.br/pesquisa/PesquisaObraForm.do ). Acceso el 03/02/2014.

13 Ibídem.

14 Vid. http://www.monumentos.art.br/monumento/a_procura_da_luz acceso en 03//02/2014). Acceso el 03/02/2014.

15 Farina, Maria S.E (2008), op. cit..

16 Ibídem.

17 Arruda Callado, Ana (2004), Maria Martins: uma biografia, Gryphus, pp.189.; Cancel, Luis R. (1988), El Espíritu latinoamericano: arte y artistas en los Estados Unidos, 1920-1970. El Museo de Artes del Bronx en asociación con H.N, Abrams, pp.344.; y Perlingeiro, Camila (2003), Escultores, esculturas, São Paulo, Edições Pinakotheke, pp.108.

18 Corrêa Silva, Rebecca., y Rosa da Silva, Ursula (2009), “La escultura de María Martins: una reflexión sobre el femenino", en I Jornadas CINIG de Estudios de Género y Feminismos. Teorías y políticas: desde el Segundo Sexo hasta los debates actuales, La Plata, Universidad Nacional de la Plata, 13 p. Véase la escultura en: http://jornadascinig.fahce.unlp.edu.ar/i2009/eje8/Correa\%20Silva. pdf. Acceso el 03//02/2014. y sensualidad del cuerpo femenino queda patente en "Yara", una sirena de agua dulce, que hechiza y seduce a los hombres y forma un "harem" de hombres en el fondo de los diferentes ríos que forman la desembocadura del Amazonas.

En 1943, realizó otra muestra en la Valentine Gallery de Nueva York. Expone 21 obras junto a Mondrian. Las esculturas de la artista tienen formas sinuosas y monstruosas que evocaban figuras mitológicas populares de la Amazonía: "Amazonía", "Cobra Grande" (Boiuna), "Yara", "Yemanjá", "Aiokã", "Yacy" y "Boto"19. Además, expone obras nuevas: "Black Madonna", "Evening in Salgueiro"; "Não te esqueças nunca que eu venho dos trópicos" 20 y "bailarina" 1 . Esas piezas funden la figura humana y la naturaleza, al punto de que se mezclan y se metamorfosean armónica y herméticamente ${ }^{22}$. Son personajes míticos, muestran el duelo entre la sexualidad femenina y masculina, el universo de la seducción del hombre a través del "Boto", y la mujer a través de la "Yara" (un pez boto hembra), "Yemanjá" y de la "Cobra Grande". Se trata de una escultura llena de pequeñas bocas y vulvas. La serpiente, monstruo que, según su ritual, mata a los hombres con sus innumerables bocas, chupa su sangre y seca su fuerza $[\underline{23}$. La víbora puede transformarse en cualquier cosa para hacer el mal, igual que la serpiente del pecado original.

Para esta exposición, María Martins preparó personalmente un catálogo en inglés cuya función didáctica era narrar sucintamente al visitante norteamericano aquellos mitos amazónicos en los que se fundamentaban sus obras. La artista siguió durante mucho tiempo trabajando con temas provenientes de las leyendas del norte de Brasil. La referencia a la naturaleza pasa a convertirse en símbolo de la potencia de lo salvaje y del deseo, en contraposición a la naturaleza dominada de la civilización occidental. Dicha fase se extiende de 1941 hasta 1946. Las esculturas muestran la violencia del deseo, del erotismo, de la inquietud que el otro puede provocar en cada persona. Estas figuras de Martins pueden leerse como un mapa de pasiones vividas y expresadas por el cuerpo, impetuoso duelo sensorial ${ }^{24}$. En otras palabras, es un rescate del aspecto bestial y primitivo del ser humano, expresan la fuerza cruda del deseo más primitivo y la sexualidad más ruda. De ahí que su iconografía resuma aberraciones que causan

19 Prandi, Reginaldo (2011), Contos e Lendas da Amazônia, São Paulo, Companhia das Letras. http:// falacultura.com/mam-maria-martins/ Acceso el 01/02/2014

20 Véase: http://jornadascinig.fahce.unlp.edu.ar/i2009/eje8/Correa\%20Silva.pdf. Acceso el03/02/2014 21 Véase: http://jornadascinig.fahce.unlp.edu.ar/i2009/eje8/Correa\%20Silva.pdf. Acceso el 03/02/2014. 22 En esa ocasión, Maria Martins compartió el espacio de la galería con su amigo Piet Mondrian (1872-1944). Mientras la brasileña logró vender casi todas sus obras, la exposición de Mondrian de la serie New York fue un fracaso. Al fin de la muestra, Maria Martins decide comprar al amigo el lienzo Broadway Boogie-Woogie, que dona al MoMA de Nueva York

23 Martins, Maria (1943), “Boina”, en Amazonia by María, Valentine Gallery, New York.

24 Costa Ramos, Ma da Graça (2002), “Erotismo Amazónico en la obra de María Martins", en Materia. Revista D Art, Universidad de Barcelona, Barcelona, pp. 149-165. 
espanto e incluso repugnancia ${ }^{25}$. Las formas retorcidas ligadas a prácticas automatistas plasman la investigación de lo ancestral. Lo primitivo que recoge de las culturas indígenas amazónicas y que, al mismo tiempo, muestran una pulsión constante entre la vida y la muerte, lo femenino y lo masculino, lo oculto y lo revelado, en una suerte de hacer visible lo invisible ${ }^{26}$.

Ya trabajando con el bronce, la escultora crea formas orgánicas cada vez más libres de cualquier figuración realista, utilizando títulos sugestivos, característica que comparte con otros artistas surrealistas ${ }^{27}$. También crea "Sem Ecos" ${ }^{28}$ y en el año siguiente "However", (1944르). En él, la serpiente del deseo comprime el cuerpo de la mujer, aprisionándola. En 1945 produce en bronce fundido la escultura “The Impossible” 30 , la obra más famosa de María Martins de la que hace varias versiones en bronce, una de ellas adquirida por el Museo de Arte Moderno de Nueva York - MoMA, en 1946. Está compuesta por seres híbridos (hombre y mujer con aspecto de animales ancestrales) que se ponen uno frente al otro sugiriendo una situación de profundo deseo, pero también de agresividad y muerte, como si señalara los límites de la unión plena entre los seres ${ }^{31}$. La artista quería mostrar la imposibilidad de la completa relación amorosa cuando el cerebro y la razón se enfrentan con los movimientos del cuerpo. Se hace imposible definir el sexo de las figuras. Puede ser que la obra esté inspirada en la pasión transgresora que vivió en primera persona la artista junto a Duchamp. Es decir son seres atormentados, pueden percibirse batallas entre cuerpos poco disciplinados, metáforas de instinto y violencia 2 .

En ese sentido, ciertos animales como la serpiente y la araña salen del universo mitológico de las leyendas amazónicas para encarnar símbolos relacionados con la vivencia de la artista. También crea "La Femme a Perdu Son Ombr" representación del cuerpo femenino la podemos encontrar en esculturas del mismo año: “Le Chemin”, “L'Ombre”, “Trop Long”, “Trop Etroit”触. Todavía en 1946, María

25 Bataille,Georges (1997), El erotismo, Barcelona, Tusquets., y Octavio Paz (1999), Um mais além do erótico, São Paulo, Sade, Mandarim.

26 Véase: http://masdearte.com/maria-martins-y-el-curioso-caso-de-las-mujeres-liberadas-enbrasil/. Acceso el 15/06/2014.

27 Perlingeiro, Camila (2003), Escultores, esculturas, São Paulo, Edições Pinakotheke, p.108.

28 Vid: http://jornadascinig.fahce.unlp.edu.ar/i2009/eje8/Correa\%20Silva.pdf. Acceso el 03/02/2014.

29 Ibídem.<

30 Ibídem.

31 Acerca de la obra de la artista afirmó: “El mundo es complicado y triste, es casi imposible que las personas se comprendan".

32 Costa Ramos, Mª da Graça (2002), op. cit., pp.149-150.

33 Véase: http:/jornadascinig.fahce.unlp.edu.ar/i2009/eje8/Correa\%20Silva.pdf. Acceso el 03/02/2014

34 Ibídem. "El camino, la sombra, demasiado largos y demasiado estrechos". sigue trabajando en cuestiones de género femenino. Esta vez el desnudo femenino da lugar a otra forma de representación, más simbólica, con la obra "Aranha" ${ }^{35}$. En el caso de "La Femme a Perdu Son Ombre", estamos ante un cuerpo de mujer con dos serpientes que salen de la cabeza, probablemente como referencia a pensamientos libidinosos. La obra, en las palabras de María, significa que "ella se liberó tanto que hasta perdió su sombra, ella no tiene nada más: es el gran peligro de la liberación, hacerse otra vez esclavo de la libertad" $\underline{36}$.

Con su poética extremadamente individualizada, Martins se presenta como una figura singular en la historia del arte moderno brasileño ${ }^{37}$. El "Cuerpo fetiche" es la toma de conciencia de los cuerpos femeninos. Muestra la flagelación o la crítica a lo fetiche, haciendo analogías o metáforas.

En 1947, María produce la obra “Implacável” $\underline{38}$, en bronce. André Breton, autor de Manifiesto surrealista, (1924) queda tan encantado con el énfasis en la fuerza de lo salvaje y del deseo que Martins da a sus esculturas que escribió en 1947:

"María, y detrás de ella - es decir, en ella - el Brasil maravilloso, donde sobre los más vastos espacios... flota todavía el ala de lo irrevelado. La puerta inmensa, apenas entreabierta sobre las regiones vírgenes donde las fuerzas intocadas, completamente nuevas, del futuro, se esconden. [...] Las angustias, las tentaciones, las agitaciones, y también las auroras, las felicidades e, incluso, de vez en cuando las puras delicias, he aquí lo que María, en bronces como "Yaci","Bouina" y "Yemanja", supo captar como nadie en su fuente primitiva. I. a la escultura del pasado o del presente" 3 .

A partir de ese periodo participa en grandes muestras del surrealismo, como Lê Surréalisme, organizada en 1947, en la Galerie Maeght, en París por el escritor francés, André Breton. Sus esculturas representan formas orgánicas, retorcidas y sensuales que evocan a las culturas arcaicas inspiradas por las leyendas y la naturaleza de las culturas indígenas amazónicas, lo que atrajo la atención de los surrealistas ${ }^{40}$. Sin duda, fue una

\footnotetext{
35 Ibídem..

36 Canada, Ma José (2006), Maria Martins: Um imaginário esquecido, São Paulo, Instituto de Arte da Universidade estadual Paulista- UNESP, p.31.

37 Schumaher, Schuma, e Vital Brazil, Érico (2000), Dicionário de Mulheres do Brasil - de 1500 até a atualidade -Bbiográfico e Ilustrado, Rio de Janeiro, Jorge Zahar.

38 Veáse: http://jornadascinig.fahce.unlp.edu.ar/i2009/eje8/Correa\%20Silva.pdf. Acceso el 03/02/2014. 39 El texto María fue escrito para el catálogo de la exposición de la artista en la Galería Julian Lévy, en Nueva York (1947) y posteriormente republicado en el libro de Breton Le Surréalisme et la Peinture.

40 Arruda Callado, Ana (2004), Maria Martins: uma biografia, Gryphus, p.189.
} 
artista influenciada por el surrealismo ${ }^{41} \mathrm{y}$ sus obras son reconocidas internacionalmente. Varias de ellas están presentes en museos de todo el mundo, entre ellos, en el Museo de Arte de Filadelfia, el Museo Metropolitano de Nueva York (MoMA), el Museo de Arte Moderno de São Paulo (MAM), el Palacio de las Artes de la Universidad de São Paulo, el Palacio de Planalto en Brasilia y el Palacio de Itamaraty en Brasilia, donde hay dos esculturas suyas: “La Femme a Perdu Son Ombre” y "O Canto da noite”, (1968)². Así como "The Road", “The Shadow”, “Toam Narrow” y “Too Long”, (1968)星.

En 1948 se traslada a París y se hace amiga de Constantin Brancusi (1876 - 1957) Benjamin Péret (1899 - 1959), Amédée Ozenfant (1886 - 1966) y Michel Seuphor (1901 - 1999) ${ }^{44}$. En la ciudad parisina, su taller se convierte en un sitio de encuentro de intelectuales. También conoce a otros artistas europeos vinculados al surrealismo y al dadaísmo, como Michel Tapiè (1909 - 1987), André Masson (1896 - 1987), Yves Tanguy (1900 - 1955) y Max Ernst (1891 - 1976) y hace otra exposición titulada: Lês statues magiques de María en la Galerie René Drouin, en París. En este mismo año interrumpió su relación amorosa con Marcel Duchamp porque la artista decidió acompañar a su marido, Carlos Martins, a su nuevo destino diplomático como embajador de Brasil en Francia, en 1948. Sin embargo, la correspondencia se prolongó en el tiempo, hasta 1951, época en que la artista ya había regresado a Brasil.

En 1949, produce “Huitième Voile” 45 , escultura en la que usó como modelo a su hija Anna María. En ella, se nota la influencia de su maestro Brancusi con un tratamiento más trabajado del material y una mayor síntesis de los volúmenes. La obra es una mujer con las piernas abiertas exponiendo la vulva en primer plano, como una gran vagina abierta en las extremidades laterales, dos "lenguas" como serpientes o plantas carnívoras listas para agarrar a quien desee penetrar. En este mismo año, Carlos Martins se jubila y regresa a Brasil con su hija, Anna María. María viaja primero a Nueva York antes de volver definitivamente al país sudamericano.

En 1950, ya en Brasil, colabora en la organización de las primeras Bienales Internacionales de São Paulo y en la fundación del Museo de Arte Moderno de Río de Janeiro (MAM/RJ). La artista solo regresa al país natal tras un largo período de

41 Brown, Betty Ann (2002), Gradiva's Mirror: Reflections on Women, Surrealism and Art History, Midmarch Arts Press, pp.302 y Louzada, Júlio (1997), Artes plásticas Brasil 97, Volumen 9, Inter/arte/ Brasil.

42 Brecheret, Vítor (1997), A escultura brasileira de 1920 a 1990: perfil de uma identidade, Centro Cultural, Banco Interamericano de Desenvolvimento, p.47. Ramos, Graça (2009), Maria Martins: excultora dos Trópicos, Artviva, p. 285., y véase: http://infomarbsb.blogspot.com.es/2011/04/ trabalho-sobre-o-itamaraty.html. Acceso el 03/02/2014

43 Véase: http://jornadascinig.fahce.unlp.edu.ar/i2009/eje8/Correa\%20Silva.pdf. Acceso el 03/02/2014 44 Seuphor, en su Dictionnaire de la Sculpture Moderne, presenta a Maria Martins como la gran escultora del surrealismo.

45 Véase: http://papelderascunho.net/?m=200708. Acceso el 03/02/2014. residencia en el exterior, durante el cual transcurrió su formación y su maduración artística. Fuera del país destacó como importante interlocutora de los maestros surrealistas, desarrolló un trabajo marcado por el rescate de elementos relativos a las mitologías nativas brasileñas y por la deformación creciente y expresiva de la figura humana. Sin embargo, su poética surrealista no fue bien recibida en el medio artístico brasileño de la primera mitad de los años 50, dominado por las cuestiones del constructivismo y del arte abstracto, que después desembocó en el Concretismo. Todo ello acarrea la posición marginal de la artista respecto a la versión dominante del arte moderno brasileño. En la cronología del arte brasileño se la considera una artista maldita, por haber sido rebelde, por desorganizar lo conocido, pervirtiendo el orden artístico. Además, la persistencia en el tema erótico-sexual provocó que sus piezas fuesen consideradas casi pornográficas.

Su primera exposición en su país natal fue titulada Maria Sculptures, 36 esculturas en el Museo de Arte Moderno en São Paulo. En este mismo año creó "A Tue-Tête"

En 1951, en la I Bienal de São Paulo, participó con 17 esculturas. En la Bienal de 1953, quedó en el segundo puesto en la categoría de escultoras tras crear "Calendrier de L'Eternité" reconocimientos, al ser galardonada con el título de mejor escultora nacional gracias a su trabajo "A soma dos nossos días" 48 .

En 1956, hicieron una retrospectiva de sus obras en el Museo de Arte Moderno de Río de Janeiro. El catálogo presentó 42 esculturas, fechadas entre 1937 y 1956. No obstante, en pocos años, al no estar sintonizada con las tendencias abstracto-geométricas predominantes, unido a problemas en las manos que le dificultaban el moldeado, abandona la escultura. Fue entonces cuando la literatura pasa a ocupar ese lugar. Como escritora firma una columna en el periódico Correio da Manhã con el nombre de "Poeira da Vida". Publica: "A Ásia Maior - O Planeta China", en 1958 y "Ásia Maior: Brama, Gandhi e Nehru", en 1960. Sin embargo, la solidez de su producción y la amplia red de relaciones no fueron suficientes para asegurarle una correcta receptividad.

Su última exposición individual tuvo lugar en 1956, en el Museo de Arte Moderno de Río de Janeiro - MAM/RJ, institución que en cuya fundación había participado. Por lo que se observa en el catálogo de la muestra, se encuentra en un clima de hostilidad, pues María Martins publica un texto que defiende la libertad de expresión del

$46 \mathrm{http} / /$ jornadascinig.fahce.unlp.edu.ar/i2009/eje8/Correa\%20Silva.pdf. Acceso el 03/02/2014 $47 \mathrm{http} / /$ jornadascinig.fahce.unlp.edu.ar/i2009/eje8/Correa\%20Silva.pdf. Acceso el 03/02/2014. 48 Cancel, Luis R. (1988),op. cit., p.47 y http://jornadascinig.fahce.unlp.edu.ar/i2009/eje8/Correa\%20 Silva.pdf. Acceso el 03/02/2014

Revista Internacional de Culturas y Literaturas, abril 2014 
artista ${ }^{49}$. No obstante, críticos importantes escriben acerca de su trabajo, como Mário Pedrosa (1900 - 1981) y Murilo Mendes (1901 - 1975). Es interesante observar que ambos críticos evidencian el desafío de unir la técnica surrealista de "automatismo psíquico" al trabajo con el bronce. El Concretismo, movimiento predominante en las artes brasileñas, se caracterizaba por piezas bien acabadas. Por ese motivo, la crítica vinculada a este movimiento empezó a exigirle unidad y cohesión. Los críticos tradicionales rechazan sus obras por creer que lo bello es indicio de lo perfecto. Una de las obras rechazadas fue: "Huit-me Voile", (1949). En ella, se muestra el cuerpo de una mujer según los cánones clásicos, pero los pies tienen garras y los genitales salientes están deformados. Esta obra, así como muchas otras, fue rechazada porque lo erótico debía ser estéticamente idealizado, el cuerpo debía exaltarse con perfección y respecto, la sexualidad debía ser discreta. Además, el surrealismo no consiguió imponerse en Brasil y los que lo ejercieron lo hicieron de una manera más lírica como Tarsila do Amaral y Cicero Días ${ }^{50}$. Pero a pesar de la crítica, se nota, además, que las esculturas de María realizadas en ese periodo se hacen más abstractas, aunque sin perder el sentido alusivo de los títulos, por ejemplo, "O Canto do Mar", (1952), y"A Soma dos Nossos Dias", (1954/1955).

A finales de la década de los 50, el gobierno brasileño encargó algunas obras a algunos artistas plásticos para adornar la ciudad de Brasilia, la nueva capital recién construida, bajo la utopía: "Igualdad social, integración nacional y nacimiento de una nueva civilización". María Martins decidió crear uno de sus monstruos, "Ritmo dos Ritmos". La escultura de bronce está en la actualidad en el Palacio de la Alvorada, en Brasília y mide 5 metros. Muestra a dos seres que se abrazan, pero tampoco es posible definir si son macho o hembra, femenino o masculino, son dos seres que se enroscan y se transforman en un solo; de la fusión nace en la cabeza una estrella. Cuando termina esta obra ya tenía 65 años y sufría de muchos dolores en la mano derecha. A pesar de todo crea su última obra, "Canto da noite", otro monstruo: una medusa inmensa y rara, que recuerda los movimientos de las plantas, los pelos salen de la cabeza revueltos envolviendo todo el cuerpo, los órganos sexuales están expuestos, la boca entreabierta y las manos transformadas en garras. Sigue el mismo modelo del abrazo posible de la soledad.

En 1964, fallece su marido, Carlos Martins. En el año de 1965, publica el libro “Dioses Malditos: Nietzsche". En 1970, el arquitecto modernista Oscar Niemayer solicitó a María Martins una escultura para la Catedral de Brasilia, pero ya estaba muy mayor y no consiguió terminarla. Fallece el 27 de marzo de 1973, con 78 años de edad.

49 En ese catálogo se publican también textos de André Breton, Benjamin Péret y Murilo Mendes. En algunas citas de Marcel Duchamp y Rainer Maria Rilke se trata el tema de la libertad del artista y su relación de hostilidad con la crítica.

50 Zanini, Walter (1983), História geral da arte no Brasil, São Paulo, Instituto Moreira Salles, p. 623.
En 1997 se hizo una exposición en São Paulo en homenaje a la escultora y que sirvió como base para la muestra de Nueva York, en 1998 en Ememerich Gallery, titulada "The Surrealist Sculpture of Maria Martins".

Si revisamos la historia de la filosofía bajo la óptica que el discurso filosófico ordena y reproduce todo el pensamiento, se advierte que en Platón, en Hegel, en Nietzsche, se repite una misma operación, la de rechazo, exclusión y marginación de la mujer. En la filosofía, la mujer está siempre del lado de la pasividad ${ }^{\underline{51}}$.

Es necesario que la mujer escriba su cuerpo, que invente la lengua inexpugnable que reviente muros de separación, clases y retóricas, reglas y códigos, es necesario que sumerja, perfore y franquee el discurso de última instancia, incluso el que se ríe por tener que decir la palabra "Silencio", el que apuntando a lo imposible se detiene justo ante la palabra "imposible" y la escribe como "fin". Las mujeres son cuerpos, y lo son más que el hombre, incitado al éxito social, a la sublimación. Más cuerpo, por tanto, más escritura. Durante mucho tiempo, la mujer respondió con el cuerpo a las vejaciones, a la empresa familiar-conyugal de domestificación, a los reiterados intentos de castrarla $\underline{52}$.

Esta vida nos invita a pensar cuál ha sido el papel de la mujer en la cultura brasileña moderna y contemporánea, en la que destacan mujeres que lucharon contra convencionalismos y desarrollaron una vida y obra de gran significado. María Martins no es un ejemplo aislado. Por nombrar sólo algunas: antes de ella Tarsila do Amaral creó la imagen pictórica del movimiento antropofágico, revolucionario en la década de los años 20 y primer símbolo de una modernidad autóctona per se, y después Lygia Clark, figura fundamental del revolucionario Movimiento Concreto y Neoconcreto, junto con Lygia Pape, fundadora también del Proyecto Helio Oiticica ${ }^{\frac{53}{}}$.

\section{REFERENCIAS BIBLIOGRÁFICAS}

Alexandrian, S., O Surrealismo, São Paulo, Editora da USP, 1976.

Amaral, Aracy A., Tarsila: sua obra e seu tempo, São Paulo, Ed. 34; Edusp, 2003.

Amorós, C., y Miguel, A., Teoría feminista: de la Ilustración a la globalización. De la Ilustración al segundo sexo, 2ª ed, Madrid, Minerva, 2007.

Antelo, R., Maria con Marcel: Duchamp en los trópicos, Buenos Aires, Siglo XXI Editores, 2006. Argan, G. C., Arte moderna, São Paulo, Companhia das Letras, 1992.

51 CIXOUS, Hélène (2001), La Risa de la medusa. Ensayos sobre la escritura, prólogo de Ana María Moix, traducción revisada por Myriam Díaz - Diocaretz, Barcelona, Anthropos, p.15

52 CIXOUS, Hélène (2001), op. cit., p.58.

53 Véase: http://masdearte.com/maria-martins-y-el-curioso-caso-de-las-mujeres-liberadas-enbrasil/. Acceso el 15/06/2014.

Revista Internacional de Culturas y Literaturas, abril 2014 
Arriaga, M., (org.) "Feminismos e Interculturalidad”, en Fernández Carro, S. “La política de lo cotidiano (arte femenino contra la ideología de esferas separadas", en $V$ Congreso Internacional de la Asociación Universitaria de Estudios de las Mujeres, Sevilla, Arcibel Editores, 2004

Arruda Callado, A., Maria Martins: uma biografia, Rio de Janeiro, Gryphus, 2004.

Brecheret, V., A escultura brasileira de 1920 a 1990: perfil de uma identidade, São Paulo, Centro Cultural, Banco Interamericano de Desenvolvimento, 1997.

Breton, A., Manifestos do Surrealismo, Rio de Janeiro, Editora Nau, 2001.

Brown, B. A., Gradiva's Mirror: Reflections on Women, Surrealism and Art History, New York, Midmarch Arts Press, 2002

Canada, Mª J., Maria Martins: Um imaginário esquecido, São Paulo, Instituto de Arte da Universidade estadual Paulista- UNESP, 2006.

Cancel, L. R., El Espíritu latinoamericano: arte y artistas en los Estados Unidos, 1920-1970, El Museo de Artes del Bronx en asociación con H.N, New York, Abrams, 1988.

Cixous, H., La Risa de la medusa. Ensayos sobre la escritura, prólogo de Ana María Moix, traducción revisada por Myriam Díaz - Diocaretz, Barcelona, Anthropos, 2001

Corrêa Silva, R. y Rosa da Silva, U., “La escultura de Maria Martins: una reflexión sobre el femenino", en I Jornadas CINIG de Estudios de Género y Feminismos. Teorías y políticas: desde el Segundo Sexo hasta los debates actuales, La Plata, Universidad Nacional de la Plata, 2009, 13 p. Disponible en: http://jornadascinig.fahce.unlp.edu.ar/i2009/eje8/Correa\%20Silva.pdf. Acceso el 03//02/2014.

Coutinho, A., (Dir.) Modernismo, vol. 6, 2ª. ed., Rio de Janeiro, Sul-americana, 1970.

De Sousa, O. T., http://www.dec.ufcg.edu.br/biografias/OtavTaSo.html. Acceso el 31/01/2014.

Farina, M. S.E., Identidade e a arte em Maria Martins, Dissertação de mestrado em Interunidades em Estética e História da arte, USP-Universidade de São Paulo, São Paulo, 2008

Fausto, B., História concisa do Brasil, Sao Paulo, Edusp, 2002.

Helena, L., Modernismo brasileiro e vanguarda, 3ª ed., Sao Paulo, Atica, 2000.

InfoMar. Trabalho sobre o Itamaraty. Disponible en: http://infomarbsb.blogspot.com.es/2011/04/ trabalho-sobre-o-itamaraty.html. Acceso el 03/02/2014.

Isto é Campanha aqui nasceu o sul de Minas, http://istoecampanha.blogspot.com.es/2011/10/ biografia-de-maria-martins.html. Acceso en: 31/01/2014.

Junior, P., O movimento modernista, Rio de Janeiro, MEC, 1954.

Lafeta, J. L., 1930: A crítica e o Modernismo, Sao Paulo, Livraria Duas Cidades, 2000.

Louzada, J., Artes plásticas Brasil 97, Vol. 9, São Paulo, Inter/arte/Brasil, 1997.

Martins, M., “Boina”, en Amazonia by María, Valentine Gallery, New York, 1943.
Monumentos de São Paulo. Disponible en: http://www.monumentos.art.br/monumento/a procura da luz. Acceso el: 03/02/2014.

Mota, M., “Movimiento antropofágico: devorar y devorarse”, en Opera Mundi, 2012, Disponible en: http://www.operamundi-magazine.com/2012/01/movimiento-antropofagico-devorary-devorarse.html. Acceso el: 02/02/2014.

Parcerisas, P., Duchamp en España: Las claves ocultas de sus estancias en Cadaqués, Madrid, Siruela, 2009, pp. 136.

Perlingeiro, C., Escultores, esculturas, São Paulo, Edições Pinakotheke, 2003, pp. 108.

Prandi, R., Contos e Lendas da Amazônia, São Paulo, Companhia das Letras, 2011.

Ramos, G., Maria Martins: excultora dos Trópicos, Rio de Janeiro, Arteviva, 2009.

Ramos-Yzquierdo, M., Maria Martins y"el curioso caso de las mujeres liberadas en Brasil", 2013. Disponible en: http://masdearte.com/maria-martins-y-el-curioso-caso-de-las-mujeresliberadas-en-brasil/. Acceso el 15/06/2014.

Seuphor, M., Dictionnaire de la Sculpture Moderne, Suisse, Ed. du Griffon, 1959.

Schumaher, S., e Vital Brazil, É., Dicionário de Mulheres do Brasil - de 1500 até a atualidade Biográfico e Ilustrado, Rio de Janeiro, Jorge Zahar, 2000.

Silva, R. C., y Da Silva, U. R., “La escultura de María Martins: una reflexión sobre el femenino”, en I Jornadas CINIG de Estudios de Género y Feminismos Teorías y políticas: desde el Segundo Sexo hasta los debates actuales, Buenos Aires, Universidad de la Plata, 2009, http://jornadascinig fahce.unlp.edu.ar/i2009/eje8/Correa\%20Silva.pdf. Acceso en 31/01/2014.

Wikipédia, Otávio Tarquinio de Sousa. Disponible en: http://pt.wikipedia.org/wiki/ Ot\%C3\%A1vio Tarqu\%C3\%ADnio de Sousa. Acceso el: 02/02/2014.

Zanini, W., História geral da arte no Brasil, São Paulo, Instituto Moreira Salles, 1983. 